Research Article

\title{
Insurance Crisis, Legal Environment, and the Sustainability of Professional Liability Insurance Market in the Construction Industry: Based on the US Market
}

\author{
Yiguang Pan $(\mathbb{D}$, Xiaomei Deng $(\mathbb{D}$, Rashid Maqbool, and Weirui Niu \\ Department of Construction Management, Tsinghua University, Beijing, China \\ Correspondence should be addressed to Xiaomei Deng; dengxm@tsinghua.edu.cn
}

Received 10 May 2019; Accepted 3 July 2019; Published 21 July 2019

Academic Editor: Yinshan Tang

Copyright (c) 2019 Yiguang Pan et al. This is an open access article distributed under the Creative Commons Attribution License, which permits unrestricted use, distribution, and reproduction in any medium, provided the original work is properly cited.

\begin{abstract}
PLI (professional liability insurance) is currently the main method used to control construction practice risk and is an important economic measure of construction industry governance. Few literatures have analyzed the sustainability of the liability insurance market. In particular, the research on the sustainability of the PLI market in the construction industry is still blank. The sustainability of the market can be identified with the equilibrium of the system over a certain period of time. From the perspective of cooperation benefits, this paper adopts evolutionary game theory (EGT) to analyze the evolutionary trends of stakeholders' behaviors and their evolutionarily stable strategy (ESS) in the PLI market of the construction industry. A case study from the history of the US PLI market evolution over nearly 100 years is taken to illustrate the stakeholder game and interpret the market evolution path, and several typical stages of the development of the US PLI market are explored. Some factors that can cause a shift in equilibrium are found. The results show that the change in the legal environment will directly affect the payoffs of the stakeholders, cause market imbalance, and trigger crisis. These findings will help out the government to regulate the market in a timely manner by improving external factors, such as by building a sound credit system and ensuring the stability of the legal system. In an equilibrium state, competitive markets can eliminate individuals with high accident rates and companies with high operating costs. Moreover, these findings will also set a base for future researches to investigate the role of insurance market and legal environment in depth while providing the intensive critical factors towards sustainable construction industry.
\end{abstract}

\section{Introduction}

The responsibility risk management of architects, engineers, builders, and other construction-related professionals, as individuals who guarantee the healthy development of the construction industry, concerns construction industry personnel as well as the overall construction industry. With the gradual deepening of industrial reform in some developing countries (for example, in China), the requirements for construction professionals are increasingly strict [1]. In addition, the externalities of construction projects are great, as are the economic loss and the social impact when an accident of practicing responsibility occurs. Heavy responsibility and high risk have become the main bottlenecks restricting the technological innovation of construction professionals. This leads professionals to increase service prices or to refuse to innovate in the face of the great risks. This situation is detrimental to the sustainability of construction industry development. It is urgent to understand the evolution of the PLI market, determine the influencing factors of market equilibrium, and formulate feasible regulatory measures to ensure the sustainable development of the construction industry. Similarly, the rapid increase in construction defect litigation is causing many national and regional insurers to limit their writings in residential construction [2]. As a result, the current insurance market for US construction professionals is one of the tightest markets historically. The surge in claims for construction defects, the increase in the complexity of risk, and the absolute necessity to control losses have become the three main forces driving the changes in the US construction market. Understanding these issues is essential to operating successfully in the 
construction arena, whether as an insurer, a professional, or the government [3].

We proposed a novel perspective using evolutionary game theory (EGT) to model stakeholders in the construction industry's professional liability insurance (PLI) market and their payoff functions to seek equilibrium in studying the development of the construction PLI market. This research aims to answer the following research questions:

(1) In the competitive market, how does the construction industry PLI evolve?

(2) How do the strategic choices of the stakeholders affect each other?

(3) What factors can cause a shift in equilibrium over time?

(4) How can system (market) be sustainability over a given period of time?

The key outcome of this study is its provision of a dynamic simulation environment for studying the influential factors contributing to the equilibrium of the construction PLI market. The balance of this paper proceeds as follows. Section 2 provides a literature review of previous insurance market equilibrium research and the application of EGT. Section 3 presents the methodology of the EGT model by analyzing the influencing factors of each stakeholder's strategy selection and providing mathematical proof and computational support of the equilibrium solution of the EGT model. Section 4 presents the model verification based on the US market, identifies the stages of different market equilibrium states, and reveals the way various influencing factors impact market equilibrium through mathematical derivation and proofs. In Section 5, two propositions of the study are discussed. At last, conclusions are given in Section 6 based on the discussion of the EGT model.

\section{Literature Review}

Over the past decades, insurance and financial crises have frequently occurred, which have had a great impact on the social economy and have aroused the interest of the scientific community [4]. PLI is different from life insurance, and its market equilibrium directly affects the sustainability of the development of the corresponding industry. The sustainability of the market can be identified with the equilibrium of the system over a certain period of time. However, PLI appears to have been studied less than the macroinsurance market, and there is a gap in the research on the dynamic equilibrium of the PLI market over a long period of time.

2.1. Equilibrium in the Insurance Market. Rothschild and Stiglitz's [5] adverse selection of the competitive insurance market model is widely regarded as one of the most important research results of the information asymmetry common value market after Akerlof [6]. Much of the later literature focused on the equilibrium of the insurance market under the condition of information asymmetry. In contrast to the single separating equilibrium in the classic Rothschild-Stiglitz insurance market, multiple separating equilibria are identified in many articles. Subsequent studies solved the problem by considering a mixed strategy [7], introducing an equilibrium concept different from the Nash equilibrium [8,9], extending the dynamic structure of the game, introducing amendments to insurance company or contractual characteristics [10-13]. In addition, the existence of equilibrium from multiple perspectives was discussed [14-17].

The above literature lacks an explicitly dynamic model that describes how insurers adjust their policies over time, although many of the proposed equilibrium concepts are motivated by dynamic interpretations. From the establishment to the popularization of the PLI market, this multiyear lag is difficult to model with traditional economic techniques; although the history of the market is well known, no comprehensive model has explained the behavior of the stakeholders of the insurance market across time. This paper tries to provide an explicitly dynamic solution to the equilibrium problem and thereby helps explain the phenomenon that arises in the real insurance market and present recommendations.

2.2. Application of EGT. The economists Neumann and Morgenstern first proposed the major formal account of classical game theory [18]. Nash hinted at the later evolutionary approach with his distinction between a "rational" and "mass action interpretation" of the equilibrium solution [19]. He assumed a population of players among which each pure strategy is employed by the "average member" of the appropriate population at a stable average frequency. EGT was first formally developed by Lewontin in evolutionary biology [20]. Subsequently, Maynard Smith defined and developed the concept of an evolutionarily stable strategy (ESS) [21-23]. Axelrod's use of game theory inspired many social scientists [24], and Sugden imported the ESS concept into economics [25]. Weibull argued that much of modern EGT is in the spirit of Nash's "mass action interpretation" [26]. Since the early 1990s, there has been an explosion of interest in evolutionary games among economists and social scientists.

Evolutionary games have considerable unrealized potential for modeling substantive economic issues [27]. They promise richer predictions than orthodox game models but often require more extensive specifications. Writing down a system of ordinary differential equations (ODEs) is a classical way to mathematically represent a deterministic dynamic process in continuous time [28]. This approach is also used in EGT, where the dynamic process in question concerns the change over time in the distribution of behaviors (strategies) in a large population of interacting individuals.

The core idea of EGT is that in interactive situations, strategy replication depends on the strategy performance in the given population. Strategy performance, as in classical game theory, is represented as payoffs assigned to all strategy profiles. However, in contrast to classical game theory, EGT 
focuses not on the decisions of individual players but on the properties of the whole population and on the effect of properties of previous populations on the future population.

From the above literature review, traditional models that have investigated stakeholder behavior have examined the equilibrium problem of the insurance market by using traditional game-theoretic approaches or by taking snapshots of stakeholders at specific points along a time horizon. However, the historical changes in the market examined in this paper represent one dynamic problem that evolved slowly and sporadically across decades, and it is a contest in which insurers and professionals had to learn and adapt as they attempted to dominate in their interactions with peers and each other.

EGT is a good method for studying PLI market equilibrium changes on a long-term scale. EGT has the natural advantage of dealing with cooperation or competition between two parties (players) and can effectively reflect the complex relationships among multiple stakeholders, such as professionals and insurers. The different strategies adopted by multiple stakeholders directly influence the equilibrium of the PLI market. In addition, EGT could be used to identify the factors that influence the evolution of market equilibrium.

\section{Evolutionary Game Model Building}

The basic assumption is that the differential equation itself does not change with time, and its practical significance is that equations corresponding to the external environment are constant. To compensate for this shortcoming and reflect the interaction between the external policy environment and the individual in the real economic system, in the fifth part of this paper, we try to change the values of the parameters of the game's income function and observe the equilibrium solution changes to reveal the way external factors influence market equilibrium. The basic assumptions of the model are as follows.

In the implementation of personal practice insurance in the construction industry, the professionals who are insured and the insurance companies operating PLI essentially comprise a group of professionals and insurance companies. Under the rules set by the government, the strategy is constantly adjusted and gradually evolving in repeated games. A relatively poor strategy is replaced with a better strategy to finally achieve a dynamic equilibrium. In this equilibrium state, the professional may or may not be insured, depending on the behavior of the insurer as well as the relevant government policies.

\subsection{Basic Assumptions}

Hypothesis 1: the main participants are construction industry-related professionals and insurance companies, and the government is the rule maker and regulator of the main game of the construction industry's individual practice insurance market. Although the market rules formulated by the government are common knowledge for both parties, participants are not able to fully acquire all the knowledge of the game structure and rules. Even if all the information is obtained, due to the differences in the knowledge and cognitive abilities of the participants, there is no guarantee that all participants will make rational decisions. This is one of the reasons for Hypothesis 2.

Hypothesis 2: both professionals and insurance companies are subject to limited rationality and information asymmetry. The bounded rationality of the game player is restrained as follows: the game player will not respond immediately according to the external policy environment, which also conforms to the lagging phenomenon of policies in the real economic system. According to the myopic hypothesis, gamers are more concerned with current interests than with future interests when adjusting strategies.

Hypothesis 3: the probability that a professional group chooses to insure is $x$, and the probability of not insuring is $1-x$. The probability that an insurance company chooses to underwrite is $y$, and the probability of noninsurance is $1-y \cdot x$ and $y$ are the frequency vectors of the strategy in the group, which can be understood as the probability that the participants choose the corresponding strategy or the ratio of the number of different strategies to the total number of people.

3.2. Model and Parameter Description. The strategy matrix and payoff matrix of professionals and insurers have the forms of Tables 1 and 2.

The payment function is expressed as

$$
\begin{aligned}
& A=p(h-q)+a-r, \\
& E=n r-m h-d, \\
& C=-p q-s, \\
& G=-b, \\
& B=-p q-a, \\
& F=-d, \\
& D=-p q, \\
& H=0 .
\end{aligned}
$$

The meaning of each parameter is shown in Table 3.

3.3. Solution of Evolutionary Stability Strategy. The expected payoff function of both parties is constructed as follows:

Step 1. Expected payoff functions of professionals.

Insured professional' expected payoffs:

$$
E_{\mathrm{PRO}}(Y)=A y+C(1-y) \text {. }
$$


TABle 1: Game strategy matrix.

\begin{tabular}{lccc}
\hline & Participants & & Insurance companies \\
& & Operated $(y)$ & Not operated $(1-y)$ \\
\hline \multirow{2}{*}{ Professionals } & Insured $(x)$ & Insured, operated & Insured, not operated \\
& Not insured $(1-x)$ & Not insured, operated & Not insured, not operated \\
\hline
\end{tabular}

TABle 2: Payoff matrix.

\begin{tabular}{lccr}
\hline & & & \multicolumn{2}{c}{ Insurance companies } \\
& Participants & Operated $(y)$ & Not operated $(1-y)$ \\
\hline \multirow{2}{*}{ Professionals } & Insured $(x)$ & $A, E$ & $C, G$ \\
& Not insured $(1-x)$ & $B, F$ & $D, H$ \\
\hline
\end{tabular}

TABle 3: Model parameter.

\begin{tabular}{|c|c|}
\hline Parameter & Description \\
\hline$r$ & $\begin{array}{l}\text { Professionals are required to pay premiums. The premium level directly affects the enthusiasm of professionals for } \\
\text { becoming insured, and the insured professionals are the source of funds that allows insurance companies to form risk pools. }\end{array}$ \\
\hline & $\begin{array}{l}\text { Professional liability accident probability. The probability of professional liability accidents is related to the kind of } \\
\text { professional and individual practice level. It is one of the most important bases for calculating premiums and an important }\end{array}$ \\
\hline$p$ & indicator for the government to measure the overall industry risk and individual skill level. For the simplified analysis and \\
\hline & $\begin{array}{l}\text { calculation, the } p \text { value is the industry average, and }(0<p<1) \text {, that is, all professionals who are insured and uninsured, } \\
\text { without considering influencing factors, such as moral hazard after obtaining insurance. }\end{array}$ \\
\hline & $\begin{array}{l}\text { Expected loss of professional liability accident. The economic losses caused by occupational liability accidents in the } \\
\text { construction industry often far exceed the fixed assets of technology-based enterprises. Once an accident occurs, the }\end{array}$ \\
\hline$q$ & enterprise may face bankruptcy, and the liability of professionals may not be implemented. For public engineering accidents \\
\hline & $\begin{array}{l}\text { in particular, the impacts of social, political, and credit issues, etc., are important factors the government is extremely } \\
\text { concerned about. }\end{array}$ \\
\hline & Credit income generated by professionals after insurance. This mainly includes the potential benefits in credit guarantees, as \\
\hline$a$ & $\begin{array}{l}\text { well as the competitive advantages in the bidding process. The size of credit benefits is related to the completeness of the } \\
\text { market credit system and the reward and punishment system formulated by the regulatory authorities. }\end{array}$ \\
\hline & Professionals are willing to become insured, but there is no suitable liability insurance product, and the result is \\
\hline & xpenditure. Professionals will transfer the risk to the service price or choose to exit the market \\
\hline$S$ & ironment with high overall risk prevention awareness, professionals will also be exposed \\
\hline & o various noninsurance risk control expenditures and indirect losses, such as limited business scope and low credit rating. \\
\hline & The amount paid by the insurance company after the professional liability accident. After the accident, the effective \\
\hline$h$ & $\begin{array}{c}\text { compensation amount of the insurance claims confirmed by both parties is usually less than the direct economic loss caused } \\
\text { by the accident. Therefore, this paper assumes that } h<q .\end{array}$ \\
\hline$n$ & $\begin{array}{c}\text { Number of professionals insured, as the more the people insured are, the larger the risk pool of the insurance company is, } \\
\text { and the stronger the company's ability to pay. }\end{array}$ \\
\hline$m$ & $\begin{array}{c}\text { Number of insured professionals who have experienced liability accidents within a certain time interval (such as one year), } \\
\text { which directly affects the insurance company's claims. }\end{array}$ \\
\hline$d$ & $\begin{array}{l}\text { PLI business underwriting start-up costs. This part mainly includes start-up costs, such as publicity, inspection, and } \\
\text { development, as well as late-stage underwriting costs. }\end{array}$ \\
\hline$b$ & Opportunity cost incurred by insurance companies without PLI business. \\
\hline
\end{tabular}

Uninsured professionals' expected payoffs:

$$
E_{\text {PRO }}(N)=B y+D(1-y) \text {. }
$$

Professionals' expected payoffs:

$$
E_{\mathrm{PRO}}=x E_{\mathrm{PRO}}(Y)+C(1-y) \text {. }
$$

Step 2. Expected payoff functions of insurance companies.

Expected payoff function of the insurance companies that choose to operate:

$$
E_{\mathrm{INS}}(Y)=x E+(1-x) F
$$

Expected payoff function of the insurance companies that choose not to operate:

$$
E_{\mathrm{INS}}(N)=x G+(1-x) H \text {. }
$$

Insurance companies' expected earnings:

$$
E_{\mathrm{INS}}=y E_{\mathrm{INS}}(Y)+(1-y) E_{\mathrm{INS}}(N) .
$$


Step 3. Formulating a replicator dynamic system.

In a replicator dynamic system, the growth rate of a strategy selected by the players should be equal to its fitness less the average fitness of all players in the population [29].

The dynamic replication equation of professionals is as follows:

$$
\begin{aligned}
F(x) & =\frac{d x}{d t}=x\left(E_{\mathrm{PRO}}(Y)-E_{\mathrm{PRO}}\right) \\
& =x(1-x)(y(A-C-B+D)+C-D) \\
& =x(1-x)(y(p h+2 a+s-r)-s), \\
F^{\prime}(x) & =(1-2 x)(y(A-C-B+D)+C-D) \\
& =(1-2 x)(y(p h+2 a+s-r)-s) .
\end{aligned}
$$

The dynamic replication equation of insurance companies is

$$
J=\left[\begin{array}{c}
(1-2 x)(y(A-C-B+D)+C-D) \\
y(1-y)(E-F-G+H)
\end{array}\right.
$$

Weibull presented the mathematical proof of various equilibrium solutions of the typical symmetric $2 * 2$ evolutional game [30]. Sun established the dynamic equations of a $2 \times 2$ asymmetric evolutionary game and topologically classified its qualitative properties to address the problem of evolutionary stability [31]. Based on the above research results, in this paper, there are 16 possible types of the original static games presented in Table 1, depending on the payoff values of each side of the game; however, we will focus primarily on four types of representative situations in our analysis.

3.4. Existence of Equilibrium. As we have identified sustainability with the long-term equilibrium of the construction industry PLI market viewed as a dynamic system, some propositions that guarantee the existence of one or more stable points with technical proof are necessary.

Theorem:

(1) The five fixed points, $E 1(0,0), E 2(0,1), E 3(1,1), E 4$ $(1,0)$, and $E 5(X, Y)$, where $X=(H-F) /(E-F-$ $G+H)$ and $Y=(D-C) /(A-C-B+D)$, are equilibrium conditions of the replicator dynamic system

(2) The equilibrium point $(0,0)$ is the ESS, if $A<B$, $C<D, E<G$, and $F<H$ (State 1$)$

(3) The equilibrium point $(1,1)$ is the ESS, if $A>B$, $C>D, E>G$, and $F>H$ (State 2$)$

$$
\begin{aligned}
F(y) & =\frac{d y}{d t}=y\left(E_{\mathrm{INS}}(Y)-E_{\mathrm{INS}}\right) \\
& =y(1-y)(x(E-F-G+H)+F-H) \\
& =y(1-y)(x(n r-m h+b)-d), \\
F^{\prime}(y) & =(1-2 y)(x(E-F-G+H)+F-H) \\
& =(1-2 y)(x(n r-m h+b)-d) .
\end{aligned}
$$

The evolution equilibrium of the construction industry PLI market can be described by a first-order differential equation set composed of equations (16) and (18) as follows:

$$
\left\{\begin{array}{l}
F^{\prime}(x)=(1-2 x)(y(A-C-B+D)+C-D) \\
=(1-2 x)(y(p h+2 a+s-r)-s), \\
F^{\prime}(y)=(1-2 y)(x(E-F-G+H)+F-H) \\
=(1-2 y)(x(n r-m h+b)-d) .
\end{array}\right.
$$

The Jacobian matrix of the system is as follows:

$\left.\begin{array}{c}x(1-x)(A-C-B+D) \\ (1-2 y)(x(E-F-G+H)+F-H)\end{array}\right]$.

(4) The equilibrium points $(1,0)$ and $(0,1)$ are the ESS, if $A<B, C>D, E<G$, and $F>H$ (State 3)

(5) The equilibrium points $(0,0)$ and $(1,1)$ are the ESS, if $A>B, C<D, E>G$, and $F<H$ (State 4$)$

Proof:

(1) According to the stability theorem of differential equations, the equilibrium point of the replicator dynamic system represented by equations (19) should satisfy $F^{\prime}(x)=0, F^{\prime}(y)=0$, so $E 1(0,0), E 2(0,1), E 3$ $(1,1), E 4(1,0)$, and $E 5(X, Y)$, where $X=(H-F) /$ $(E-F-G+H)$ and $Y=(D-C) /(A-C-B+D)$, are equilibrium conditions of the replicator dynamic system.

(2) According to the constraints given by Theorem 2, it is known that the (no insurance and no business) strategy has higher returns than other strategies and is the only pure strategy Nash equilibrium of the original game in Table 2. There is no prisoner's dilemma game of potential cooperative interests in the original game. Therefore, the subgame perfect Nash equilibrium of the infinite and finite repeated games in this model is the Nash equilibrium of the original game. In addition, the equilibrium stability of each point can be judged by the determinant and trace of its Jacobian matrix $J$ (equation (20)). When $A<B, C<D, E<G, F<H$, 
$\operatorname{Det}(J)>0$, and $\operatorname{Tr}(J)<0, E 1(0,0)$ is the only ESS of State 1.

(3) In the same way, when $A>B, C>D, E>G, F>H$ (State 2$), \operatorname{Det}(J)>0$, and $\operatorname{Tr}(J)<0$, it can be proved that (insured, operated) E3 $(1,1)$ is the ESS of State 2.

(4) When $A<B, C>D, E<G$, and $F>H$ (State 3 ), the equilibrium points are $E 2(0,1), E 4(1,0), \operatorname{Det}(J)>0$, and $\operatorname{Tr}(J)<0$, so $E 2(0,1)$ and $E 4(1,0)$ are both ESS.

(5) When $A>B, C<D, E>G$, and $F<H$ (State 4), the equilibrium points are $E 1(0,0), E 3(1,1), \operatorname{Det}(J)>0$, and $\operatorname{Tr}(J)<0$, so $E 1(0,0)$ and $E 3(1,1)$ are both ESS.

There are five possible equilibrium points for the replicator dynamic system: $E 1(0,0), E 2(0,1), E 3(1,1), E 4(1,0)$, and $E 5(X, Y)$, where $X=(H-F) /(E-F-G+H)$ and $Y=(D-C) /(A-C-B+D)$. Whether the equilibrium points are the ESS depends on the relative size of the payoff function $(A, B, C, D, E, F, G$, and $H)$ value. Its numerical relative size is determined by the value of each parameter in Table 3; namely, the real economic system corresponding to each parameter value determines the market equilibrium, and the determinant and trace of each equilibrium point in different states are shown in Table 4.

\section{Model Verification Based on the US Market}

Taking the development of the US PLI market as an example, the initial market state is (not insured, not operated), and the state gradually develops into (insured, operated). In the period of rapid development, full insurance coverage of all professionals is not reached, and all insurance companies are underwriting, which is the perfect state but is affected by various internal and external factors in a dynamic process. During insurance crisis, the availability crisis and affordability crisis have great research value. In a market experiencing availability crisis, many insurance companies are bankrupt, and professionals cannot purchase liability insurance. In a market experiencing affordability crisis, there are insurance products on the market, but premiums are too expensive for professionals to afford [32]. The essence of the crisis is the abnormal evolution of the game strategy and the market imbalance. Therefore, in this paper, we select four representative states of the US construction industry PLI market development for analysis, as shown in Figure 1.

A PLI for architects existed in the US since as early as 1950 [33]. Despite over half a century of development, the US construction PLI market remains in constant reflection, reform, and development after undergoing start-up growth, profit, and crisis. Many scholars have conducted in-depth research on the market's development, and their results have contributed valuable insights. This paper mainly takes the relatively mature American PLI market as the object, systematically traces its market development trajectory, and provides reasonable suggestions for the balanced development of the PLI market in the construction industry.

4.1. Stage 1: Early Market. The period before 1950 can be regarded as the development stage of the basic theory of PLI in the construction industry. The literature on PLI for the construction industry at this time was rare and mainly included works by doctors, lawyers, accountants, and PLI companies. Most of the theoretical research at this stage was published in journals of law and economy, which shows that the establishment of the liability insurance market must be accompanied by a complete economic and legal system.

The literature mainly focuses on professional liability risk classification, economic principles, types of insurance, and other basic theories [34]. The function and significance of insurance are expounded from social value, ethics, and morality [35]. Mulligan provided a large number of real cases and systematically expounded on the specific legal issues in the practice and operation of insurance [36]. Concerning the problems of prevention of various injury accidents and compensation for victims' loss caused by industrial expansion, James proposed that the development of liability insurance can solve the above problems and analyzed the legal problems caused by the implementation of the liability insurance system. He expressed doubts about the accident prevention effect of liability insurance and presented specific improvement measures [37]. He also explained the specific terms of the liability insurance contract from a legal perspective based on a real liability insurance judgment case [38].

Specifically concerning PLI, at a special committee meeting in 1924, the New York Medical Association issued a recommendation for doctors engaged in radiation diagnosis and treatment to take precautionary measures, disclaimers, insurance transfer, and other risk control measures to prevent medical liability accidents [39]. At that time, the importance of adequate PLI coverage became increasingly obvious to physicians, which led to the rapid and progressive increase in premiums for such insurance since World War II. These problems, together with the growing complexity of the field and the increasing number of claims, settlements, and judgments, make it mandatory for the physician to know whether he is adequately protected. In response to this problem, Joseph proposed very specific and detailed measures in terms of underwriting significance, insurer selection, type of underwriting, scope of coverage, disclaimer, and withdrawal clauses [40]. At the same time, judges, legislators, and other judicial personnel reached a consensus on the unique nature of insurance contracts and the public service role of the insurance industry. Insurance was believed to have externalized and standardized many cumbersome technologies and could be better used as a fair and effective way to allocate the losses of various types of liability accidents. The risk management function of insurance was particularly emphasized in the hope that liability insurance will develop into a more applicable social governance tool [41]. Relyea noted that the legal proceedings against municipal engineering companies undertaking government public work construction projects could avoid the legal blind area at that time by purchasing liability insurance [42].

4.1.1. State 1: Initial State of the Market. In the market, the professional is not insured, the insurer is not operating (not insured, not operated) is the only pure strategy Nash 
Table 4: Determinant $\operatorname{Det}(J)$ and trace $\operatorname{Tr}(J)$ of the equilibrium point under various state conditions.

\begin{tabular}{|c|c|c|c|c|c|c|c|c|c|}
\hline Balance & $\begin{array}{c}\text { Determinant } \operatorname{Det}(J) \\
\text { Trace } \operatorname{Tr}(J)\end{array}$ & & State 1 & & State 2 & & State 3 & & State 4 \\
\hline$E 1(0,0)$ & $\begin{array}{c}(C-D)(F-H) \\
C-D+F-H\end{array}$ & $\begin{array}{l}+ \\
-\end{array}$ & ESS & $\begin{array}{l}+ \\
+\end{array}$ & Unstable & $\begin{array}{l}+ \\
+\end{array}$ & Unstable & $\begin{array}{l}+ \\
-\end{array}$ & ESS \\
\hline$E 2(0,1)$ & $\begin{array}{c}(A-B)(H-F) \\
A-B+H-F\end{array}$ & $\begin{array}{l}- \\
\end{array}$ & Unstable & $\begin{array}{l}- \\
- \\
*\end{array}$ & Unstable & $\begin{array}{l}+ \\
-\end{array}$ & ESS & $\begin{array}{l}+ \\
+\end{array}$ & Unstable \\
\hline E3 $(1,1)$ & $\begin{array}{c}(B-A)(G-E) \\
B-A+G-E\end{array}$ & $\begin{array}{l}+ \\
+\end{array}$ & Unstable & $\begin{array}{l}+ \\
-\end{array}$ & ESS & $\begin{array}{l}+ \\
+\end{array}$ & Unstable & $\begin{array}{l}+ \\
-\end{array}$ & ESS \\
\hline$E 4(1,0)$ & $\begin{array}{c}(D-C)(E-G) \\
D-C+E-G\end{array}$ & $\begin{array}{l}- \\
- \\
\end{array}$ & Unstable & $\begin{array}{l}- \\
* \\
*\end{array}$ & Unstable & $\begin{array}{l}+ \\
- \\
\end{array}$ & ESS & $\begin{array}{l}+ \\
+ \\
\end{array}$ & Unstable \\
\hline$E 5(X, Y)$ & $\begin{array}{c}(H-F)(E-G)(C-D)(A-B) /(E-F-G+ \\
H)(A-C-B+D) \\
0\end{array}$ & $\begin{array}{l}* \\
0\end{array}$ & Unstable & $\begin{array}{l}* \\
0\end{array}$ & Unstable & $\begin{array}{l}+ \\
0\end{array}$ & Saddle point & $\begin{array}{l}+ \\
0\end{array}$ & Saddle point \\
\hline
\end{tabular}

*Uncertainty; when $\operatorname{Det}(J)>$ and $\operatorname{Tr}(J)<0$, this point is ESS; (3) when $\operatorname{Det}(J)>$ and $\operatorname{Tr}(J)=0$, this point is the saddle point.

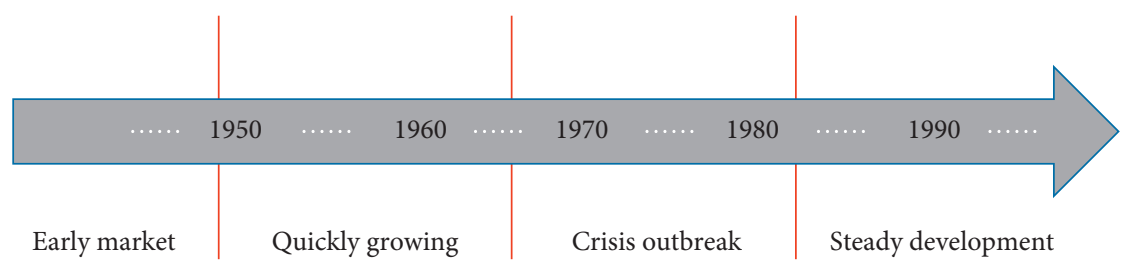

Figure 1: Market development trajectory.

equilibrium solution, and the corresponding profit value constraint is $A<B, C<D, E<G$, and $F<H$.

4.2. Stage 2: Market Expansion. The time span of this stage is from 1950 to 1970 . It can be regarded as the growth period of the development of the PLI market in the construction industry. Since the 1960s, the US construction industry PLI market has expanded rapidly. It first appeared for architects beginning in 1950, and by 1970, PLI had extended to basically all types and scope in the US construction industry.

However, the lack of systematic planning and the blind and reckless expansion of PLI also laid a hidden danger that would lead to the outbreak of insurance crisis.

4.2.1. State 2: Period of Rapid Development. The market expands rapidly. A large number of professionals participate in insurance, insurance companies develop new types of PLI, the market trend (insured, operated) growing rapidly (insured, operated) is the only pure strategy Nash equilibrium and the corresponding profit value constraints are $A>B$, $C>D, E>G$, and $F>H$.

4.3. Stage 3: Insurance Crisis. At this stage, the research results concerning basic theories are very rich. This paper focuses on the literature on the crisis of the liability insurance market and analyzes the main causes of market imbalance.

Since the 1970s, there have been three major liability insurance crises in the US. The PLI crisis that broke out in the 1970s and 1980s has the widest range, involving medical, nursing, municipal, law, accounting, civil aviation, and other industries. The crisis that broke out in early 2000 mainly focused on the medical liability insurance field [43]. The construction industry was not immune to these two crises; the great impact of the collapse of insurance companies undertaking construction-related liability insurance, the rise of PLI premiums, the sharp reduction of construction industry profits, and the loss of construction talents remains to the present [44]. After the outbreak of the second liability insurance crisis in the US in the 1980s, the government sets up a special investigation team to comprehensively investigate and analyze the liability insurance crisis, believing that the development of tort law was the main cause [32]. Tort law impacts the insurance market mainly in that the development of no-fault liability will expand the scope of tort liability indefinitely while protecting the interests of victims [45]. Many more companies and individuals who are not directly responsible for the fault are made responsible for the loss of the victim [46]. The reason for the outbreak of the liability insurance crisis cannot be explained by only one theory or principle, but there is consensus that the expansion of tort liability range is an important cause. Many studies have explained the mechanism of action between tort law and liability insurance crisis [47-51]; While the construction-related professional liability used to be limited to damage caused by negligence during construction practice, the change of the tort liability law extended the responsibility of the engineer to aspects such as construction site safety, third-party damage, and product liability. These aspects are clearly beyond the scope of professional responsibility and represent a great challenge for construction industry professionals [52]. In addition, with the misinterpretation of the 
causation of fault liability, the legal atmosphere is increasingly inclined towards the victims of professional accidents, and the poor operation of the insurance industry is another important cause of the crisis [51, 53-55].

Of course, the reasons for the outbreak of the crisis cannot be attributed solely to external factors. The US construction industry also has many problems in terms of risk management and control. For example, the application of new materials that has not fully been demonstrated and tested increases the probability of potential victims and a tort damage lawsuit. The increasingly complex modern construction technology has increased the difficulty of identifying tort liability and invisibly increased the operating cost of the tort liability system. Nevertheless, the construction industry has followed the traditional risk prevention and control measures of professional responsibility and failed to adapt quickly to the development of tort law. The limitations of the relevant professionals' engineering thinking, coupled with the lack of legal literacy, place such professionals at a disadvantage when facing the potential threat of litigation [33].

4.3.1. State 3: During the Crisis Shock. After rapid growth, internal and external conditions change, the negative effects of the high-speed growth begin to emerge, the market goes into shock, and availability and affordability crises arise; namely, (insured, not operated) and (not insured, operated) are the equilibrium strategies and corresponding profit constraint conditions for $A<B, C>D, E<G$, and $F>H$.

4.4. Stage 4: Steady Development. Since 1990 and after the two PLI crises, the construction industry continued to reflect. During this period, much literature concerned the specific issues of the types, scope, prevention, and control of the occupational liability risks in the construction industry and provided rich theoretical guidance for the healthy and balanced development of the insurance market. Since 2000, the medical PLI market has been the main market, and a third crisis has broken out. During this crisis, the construction industry PLI market has relatively been stable and shown good capability of risk prevention and control, and the theoretical achievements during this period are worth learning from.

After the crises, the construction industry PLI market enters the consolidation adjustment period, and the premium price generally rises. The questions whether the professional personnel of the relevant construction industry should buy PLI and how to decide become a general problem in the construction industry. Rubin gave some very practical advice [55]. Many studies have conducted research on the scope of the professional responsibilities of various construction industry professionals, such as architects and structural engineers, as well as on the division of responsibility among relevant parties of a project and specific measures for risk prevention and control [56-59]. Day [46] and Caine and Tomas [60] analyzed the judgment standard of professional liability negligence, and High and Rossler noted that the US construction industry has experienced the phenomenon of employees moving to small companies or individual firms. In the past, litigation against a company has also turned to a large number of individuals, and the best response is to strengthen the knowledge and education of risk prevention and control and improve the legal awareness of employees [61]. After the crisis period, the proportions of organizational forms of PLI companies also changed. During the crisis, a large number of joint-stock companies went bankrupt, and various mutual insurance companies with industry association backgrounds entered the market. The cost advantage of mutual insurance companies allowed them to rapidly expand their business. At the end of the crisis, the proportion of mutual insurance companies in the PLI market rose sharply, reflecting a strong risk tolerance $[48,54]$.

In this stage of the construction industry, the importance of strengthening the industry's own professional liability risk control ability was realized. The coverage of external factors was narrowed, and insurance premiums rose, but by optimizing the terms of the contract, the parties' responsibilities were limited, communication and coordination were strengthened, risk prevention and control through measures such as education were implemented, and the professional liability accident probability was reduced. At the same time, states in the US implemented tort law reform in response to the liability insurance crisis, adopted reform measures such as limiting noneconomic loss claims, strengthening insurance regulation, and optimizing the legal environment and to some extent promoted the balanced development of the PLI market in the construction industry [49, 62-64].

4.4.1. State 4: Consolidation Period. In the aftermath of the crisis, the government reforms the game by reviewing decisions, and the market enters the adjustment period. At this point, some of the professionals in the market choose to be insured, and others choose not to be; a certain proportion of insurers likewise choose to operate, and others choose not to; the corresponding profit constraint conditions are $A>B$, $C<D, E>G$, and $F<H$.

4.5. Results of the Numerical Simulation. According to the initial conditions of each state, MATLAB is used to simulate the phase diagram of the strategy evolution, as shown in Figures 2(a)-2(d). The simulated strategy evolution path is consistent with the strategy evolution path of both parties in the US construction industry PLI market.

\section{Discussion}

By substituting and analyzing the factors that affect the payoff function, the following results can be drawn.

5.1. Proposition 1. When the premium expenditure of the professional purchasing PLI $(r)$ is greater than the sum of the expected compensation income $(p h)$ and the incremental credit income (2a), the sum of the cost of the PLI and the compensation expense $(d+m h)$ is greater than the sum of the premium income and the opportunity cost of not being insured 


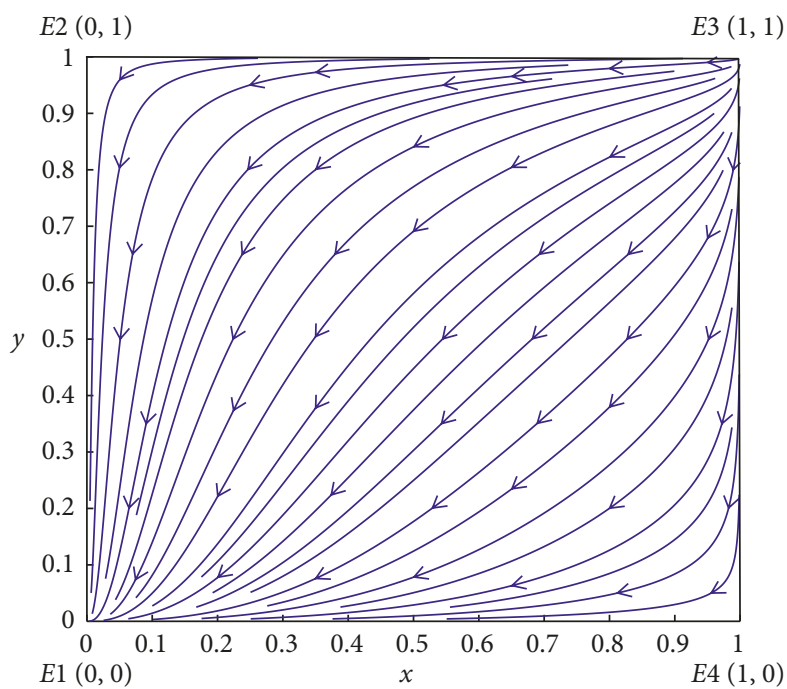

(a)

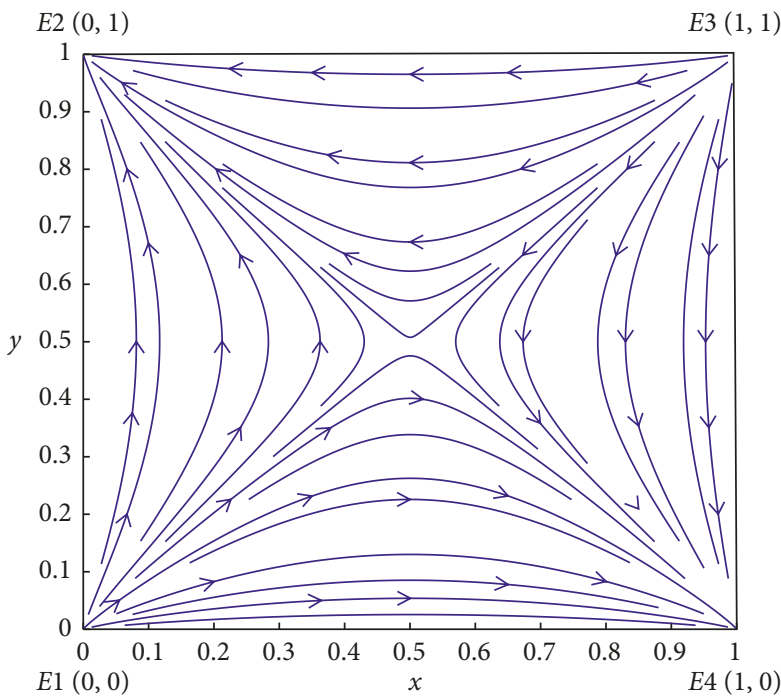

(c)

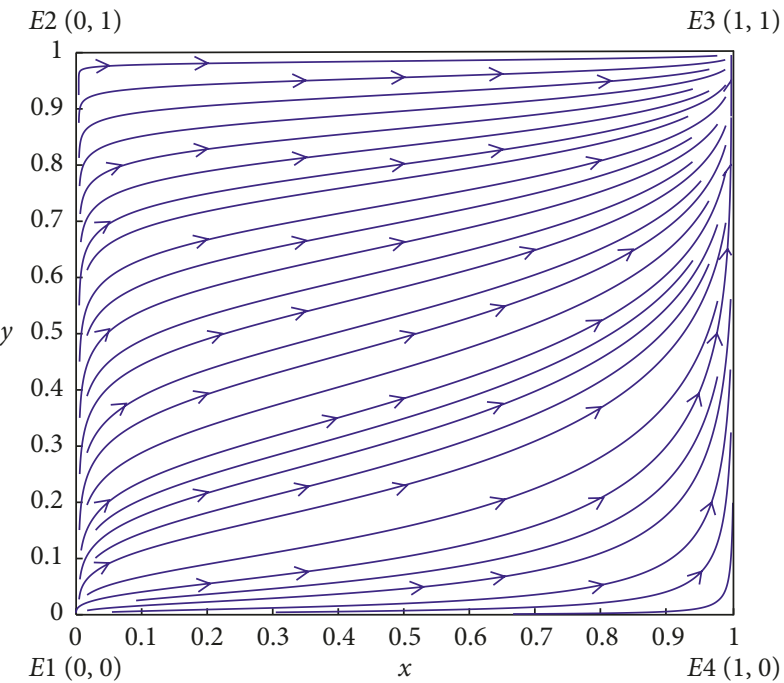

(b)

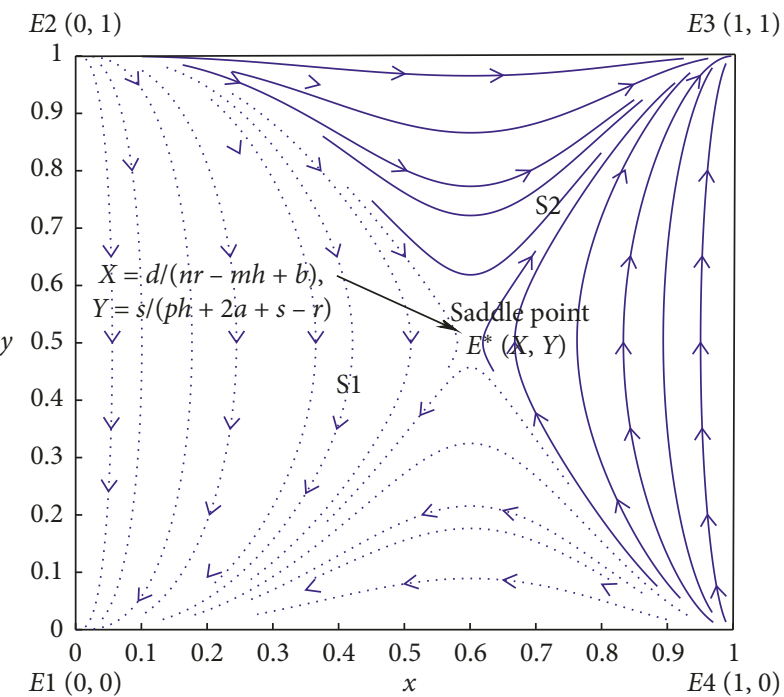

(d)

Figure 2: Evolution phase diagram of States (a) 1, (b) 2, (c) 3, and (d) 4 .

$(n r+b)$; simultaneously, the risk control expenditure cost of the uninsured professional and the insurance party's liability insurance operating cost are abnormal $(d<0$ and $s<0)$, and (insured, not operated) and (not insured, operated) are ESSs. At this time, the market will present an imbalance between supply and demand, and there is great possibility of crisis.

Proof. $A<B$ can be obtained from formulas (1) and (5), when $r>p h+2 a ; E<G$ can be obtained from formulas (2) and (4), when $d+m h>n r+b$; and $C>D$ and $F>H$ from formulas (3) and (6)-(8), when $s<0, d<0$. At this time, $\operatorname{Det}(J)>0$ and $\operatorname{Tr}(J)<0$ are present at the equilibrium points of $E 2$ and $E 4$. Therefore, under the constraint conditions in conclusion 1, E2 (not insured, operated) and E4 (insured, not operated), are the ESSs, and conclusion 2 is proven.

Discussion. In the early stage of market development, the payoffs of the strategy (not insured, not operated) are greater than those of other strategies, so the only pure strategy Nash equilibrium solution of state 1 (not insured, not operated) is a dominant strategy (Figure 2(a)). However, during the evolution from State 1 (Figure 2(a)) to State 2 (Figure 2(b)), the noninsurance risk control expenditure cost of the professional changes from $s>0$ to $s<0$, and the insurer's operating cost changes from $d>0$ to $d<0$. In the real economic system, the minimum value of the noninsurance risk control expenditure of the professional should be 0 , and the minimum operating cost of the insurance company should be 0 . The practical significance of the abnormal change in these two parameters is that the professional insurance demand at State 2 (Figure 2(b)) is satisfied, and furthermore, additional income can be obtained from the risk transfer; the average cost of the insurance company is negative; that is, the industry as a whole is generally profitable. As long as an insurance company enters the market, it will have profit. This is consistent with the economic bubble 
that occurs during the rapid development of the industry. After the market enters State 2 (Figure 2(b)), if the government does not intervene in these two parameters and the market develops freely, the persistent anomaly will cause State 2 (Figure 2(b)) to evolve into State 3 (Figure 2(c)) and finally enter the crisis phase.

In State 3 (Figure 2(c)), the uncertainty of decisionmaking between the two parties increases significantly. Compared with State 2 (Figure 2(b)), the two parameters of professionals' noninsurance risk control expenditure cost and insurance companies' operating cost are still abnormal, but the two players' cooperation strategy (insured, operated) is degraded to an unsteady state. The payoff values show that it is not an absolute dominant strategy for the insurers to choose to operate in State 3 (Figure 2(c)). This is reflected in the real market; that is, an insurance company with excessive operating cost will opt out or go bankrupt, and some insurance companies will make up for the loss of income by raising premiums. Although this is in line with the market-led governance principle, if the market develops freely, the scope of the crisis will inevitably expand. The direct impact on market performance is the drastic reduction of the number of insurance companies that operate the PLI business, which leaves a small number of insurance companies that continue to operate, greatly increased premiums, and professionals who cannot afford the high premiums, which in turn leads to availability and affordability crises.

5.2. Proposition 2. Under the condition that the endogenous variables of the insurance market remain unchanged, the adjustment of credit income $(a)$ and opportunity cost $(b)$ can promote the balanced development of both parties, leading to cooperation and a win-win situation. In the case of a constant policy environment, the insurance company's underwriting cost $d$, the probability of risk $p$, the premium $r$, and the accident probability $p$ are the main factors that restrict the cooperation between the two parties.

Proof. from equations (11) and (15), the professionals' expected payoffs are $F\left(E_{\mathrm{PRO}}\right)=x(1-x)(y(p h+2 a+$ $s-r)-s)$, assuming that the endogenous variables of the two are unchanged. By deriving the benefit variable $a$, $F^{\prime}(a)=2\left(x y-x^{2} y\right)$ can be obtained, and because $0<x<1,0<y<1,2\left(x y-x^{2} y\right)>0, F(a)$ is an increasing function. Namely, keeping the other endogenous variables constant, increasing credit income $(a)$ can encourage professionals to choose the cooperation strategy and become insured; from formulas (14) and (17), the insurance company expects the return of income $F\left(E_{\mathrm{INS}}\right)=y$ $(1-y)(x(n r-m h+b)-d)$. In the same way, taking the opportunity cost $b$ as an independent variable and deriving it, $F^{\prime}(b)=x y-x y^{2}$ because $0<x<1,0<y<1$, and $x y-x y^{2}>0$, so $F(b)$ is the speed increase, that is, the opportunity cost $b$ increases, which can impact the company's cooperation strategy. The same method can prove exogenous in the policy environment. Under certain variable conditions, the insurance company's underwriting cost $d$, the probability of risk $p$, and the premiums $r$ and accident probability $p$ paid by professionals are the main factors restricting the cooperation between the two parties. This situation will not be repeated here.

Discussion. The evolution the phase diagram of State 4 in Figure 2(d), the meaning of mapping to the real market environment, shows that the dotted area S1 (Figure 2(d)) encloses $E 1, E 2, E 5$, and $E 4$, and the evolution of the two sides will eventually degenerate to the state (not insured, not operated). In contrast, in solid line area S2 (Figure 2(d)), the strategic evolution of both parties will eventually tend to the (insured, operate) cooperation strategy, which is the optimal situation for cooperation and mutual benefit. The proportional distribution of the two strategies depends on the specific position of the saddle point $(X, Y)$ value, and the market equilibrium state can be regulated by adjusting the factor value that affects the saddle point.

During the evolution from State 3 (Figure 2(c)) to State 4 (Figure 2(d)), the US government adopted various policy measures to resolve the insurance crisis. For example, the establishment of the maximum limit of infringement compensation and the optimization of the legal environment are reflected in the model, which influences the exogenous variables. The benefits to all parties will correct the evolution paths of all parties and avoid further expansion of the market imbalance. For example, in terms of credit benefits, after the Second World War, the US began to build a credit information system. The importance of credit ratings has become deeply rooted; the credit ratings of individuals and enterprises directly affect their lives and various business activities. Its importance is also consistent with the results of theoretical analysis. At the same time, the accident probability or risk probability $p$ can be observed from the model analysis. Because this endogenous variable is shared by both parties in the market, the probability of accident occurrence $p$ is reduced, with positive effects on the return value of cooperative decisionmaking (insured, operated). Both parties to the insurance have a common interest. The insurer can use various economic means to motivate professionals to reduce the probability of occupational liability accidents, thereby realizing the market governance function of insurance. Moreover, in the second part of the literature review, we found that the US government did not directly intervene in endogenous variables, such as underwriting costs and premiums, nor did it mandate that professionals must purchase PLI, more often through the insurance market. This reflects the survival of the fittest by adjustment and contributes to the high degree of marketization of the US PLI competition.

Here, the exogenous variable credit income $a$, opportunity cost $b$, and two policy variables are selected for simulation analysis, and Proposition 2 analysis results are verified. Keeping other parameters constant, increasing the values of $a$ and $b$, and iterating 50 times (Figures 3(a) and 3(b)), the effect of external factors on the strategy evolution of both parties can be obtained. The convergence speed of cooperation between professionals and insurers is accelerated. When $a=6$ and $b=5$, only 5 repeated games are required, and both sides choose the cooperation strategy. 


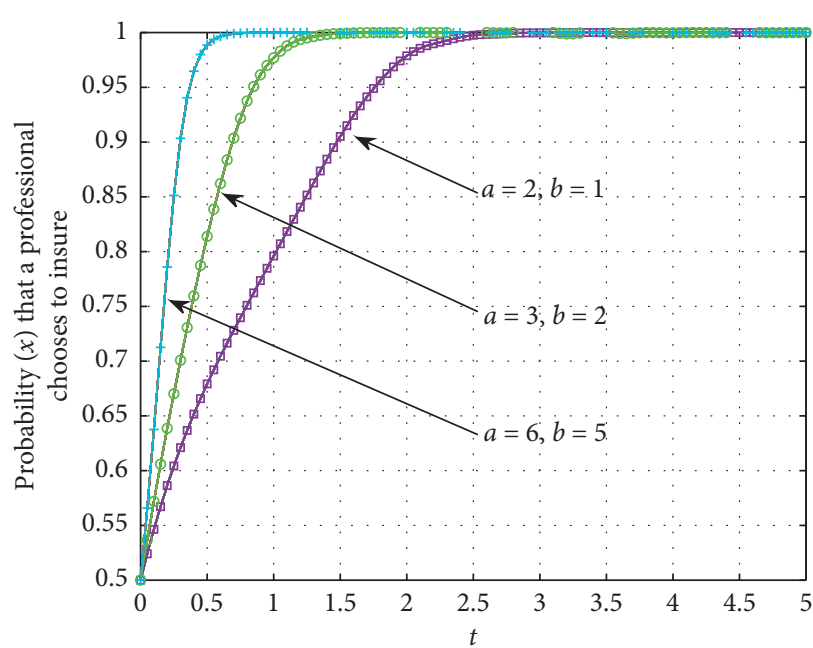

(a)

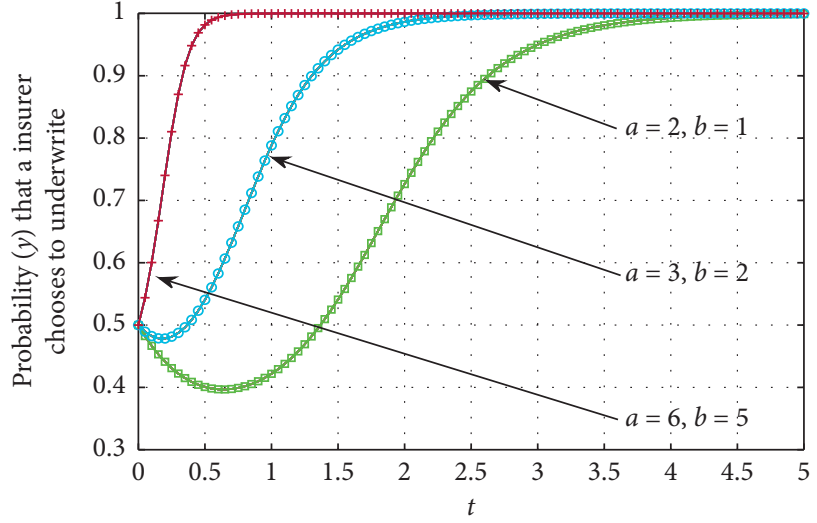

(b)

FIGURE 3: The impact of credit income (a) and opportunity cost (b) on the evolution of (a) professional's strategy and (b) insurer's strategy.

\section{Conclusions}

The results of the EGT model are consistent with the findings in the case study of the historical development of the US construction PLI market. An ESS of cooperation for stakeholders influenced by many internal and external factors, especially change in the legal environment, will directly affect the payoffs of the stakeholders, cause market imbalance, and trigger crisis; therefore, maintaining the stability of the legal system is crucial to the stability of the liability insurance market. In addition, individual stakeholder factors, such as the frequency of occupational liability accidents, operating costs, and insurance premiums, will influence the evolution of market equilibrium.

In the market, stakeholders have different evolutionary stability strategies in different external environments. The corresponding market shows equilibrium or crisis states, and the system changes from one phase to another. The phase diagram of the changes throughout the four stages in Figures 2(a)-2(d) shows that the phase corresponding to the crisis state (Figure 2(c)) may be catastrophic for the insurance market, and a relatively chaotic crisis status must be avoided. A clear strategy to prevent entry into the crisis state concerns government action: when the market is overheated and some factors are abnormal, the government should promptly intervene and reset the parameters. The best practice of this intervention is reform and innovation, potentially by government institutional reforms, and includes technological innovation by professionals and insurers. Therefore, it is necessary for the government to regulate the market in a timely manner by innovations, such as building a sound credit system and ensuring the stability of the legal system.

When the market is in a stable equilibrium state (Figure 2(d)), professionals with excessive accident probability and insurers with excessive operating costs will be eliminated by the market. A good institutional environment, timely reform of the government, and technological and management innovations of professionals and insurers are the main measures to promote the sustainable and healthy development of the liability insurance market.

The civil engineer and other professionals are nowadays exposed to floodgates of "liability in an indeterminate amount for an indeterminate time to an indeterminate class." Professional liability insurance is perhaps the ultimate option to which a civil engineer may resort to protect himself, his firm, and his clients against hazards that might eventuate as a result of errors, omissions, or breaches of professional duty. Furthermore, from a technological innovation aspect, the only way in which professional men can safeguard themselves against ruinous liability from high-risk technological innovation is also by insurance.

The contributions of this study are two-fold; practical and theoretical. The findings will lead the way for the government to formulate strategies for regulating the market through effective credit system while ensuring the stability of the legal system. In addition, the findings will also be effective in an equilibrium state where competitive markets can eliminate individuals with high accident rates and companies with high operating costs. Moreover, the findings of this study will also provide insights into future researches to investigate the role of the insurance market and legal environment while providing an effective environment towards the sustainable construction industry.

This article has certain limitations. For example, this article only analyzes the evolution of the macroinsurance market and does not propose specific methods for individual professionals. Moreover, this article clearly explains the interaction between the construction industry, insurance, and law. Future research will focus more on the specific methods of individual professional responsibility risk control, and how is the risk of occupational liability divided among the respective professionals in the project. Moreover, due to the limitations of the length of the article, the role of occupational liability insurance in promoting technological 
innovation in the civil engineering industry is not explained too much. Future research may also explore the link between occupational liability and technical innovation in the civil engineering industry.

\section{Data Availability}

No data were used to support this study.

\section{Disclosure}

Any opinions, findings, and conclusions or recommendations expressed in this material are those of the authors and do not necessarily reflect the views of the sponsors.

\section{Conflicts of Interest}

The authors declare that they have no conflict of interest.

\section{Authors' Contributions}

Yiguang Pan conceptualized the study, formulated the methodology, analyzed the data using software, performed formal analysis and investigation, and prepared the original draft. Xiaomei Deng validated the experiment. Rashid Maqbool and Yiguang Pan reviewed and edited the manuscript. Yiguang Pan and Weirui Niu visualized the results. Xiaomei Deng supervised the study.

\section{Acknowledgments}

This study was supported in part by the National Natural Science Foundation of China under Grant nos. 71872094 and 71473145 .

\section{References}

[1] B.-J. He, D.-X. Zhao, J. Zhu, A. Darko, and Z.-H. Gou, "Promoting and implementing urban sustainability in China: an integration of sustainable initiatives at different urban scales," Habitat International, vol. 82, pp. 83-93, 2018.

[2] P. Zhang, G. Qin, and Y. Wang, "Optimal maintenance decision method for urban gas pipelines based on as low as reasonably practicable principle," Sustainability, vol. 11, no. 1, p. 153, 2018.

[3] A. Z. De Padua, "Crush of defect claims persists in construction insurance market," National Underwriter, no. 4, pp. 18-22, 2004.

[4] A. Trujillo-Ponce, R. Samaniego-Medina, and C. CardoneRiportella, "Examining what best explains corporate credit risk: accounting-based versus market-based models," Journal of Business Economics and Management, vol. 15, no. 2, pp. 253-176, 2013.

[5] M. Rothschild and J. Stiglitz, "Equilibrium in competitive insurance markets: an essay on the economics of imperfect information," Quarterly Journal of Economics, vol. 90, no. 4, pp. 629-649, 1976.

[6] G. A. Akerlof and A. George, "The market for "lemons": quality uncertainty and the market mechanism," Quarterly Journal of Economics, vol. 84, no. 3, pp. 488-500, 1970.
[7] P. Dasgupta and E. Maskin, "The existence of equilibrium in discontinuous economic games, i: theory," Review of Economic Studies, vol. 53, no. 1, pp. 1-26, 1986.

[8] C. Wilson, "A model of insurance markets with incomplete information," Journal of Economic Theory, vol. 16, no. 2, pp. 167-207, 1977.

[9] J. G. Riley, "Informational equilibrium," Econometrica, vol. 47, no. 2, pp. 331-359, 1979.

[10] M. Hellwig and W. Leininger, "On the existence of subgameperfect equilibrium in infinite-action games of perfect information," Journal of Economic Theory, vol. 43, no. 1, pp. 55-75, 1987.

[11] M. Hellwig, "Some recent developments in the theory of competition in markets with adverse selection," European Economic Review, vol. 31, no. 1-2, pp. 319-325, 1987.

[12] R. Inderst and A. Wambach, "Competitive insurance markets under adverse selection and capacity constraints," European Economic Review, vol. 45, no. 10, pp. 1981-1992, 2001.

[13] W. Mimra and A. Wambach, "A game-theoretic foundation for the wilson equilibrium in competitive insurance markets with Adverse selection," in IDEAS Working Paper Series from $R e P E c, 2011$.

[14] K. Borch, "Equilibrium premiums in an insurance market," Journal of Risk and Insurance, vol. 51, no. 3, pp. 468-476, 1984.

[15] M. E. Chernew and K. D. Frick, "The impact of managed care on the existence of equilibrium in health insurance markets," Journal of Health Economics, vol. 18, no. 5, pp. 573-592, 1999.

[16] A. Y. Golubin, "Pareto optimality and equilibrium in an insurance market," ASTIN Bulletin, vol. 38, no. 2, pp. 441-459, 2008.

[17] J. W. Liu and M. J. Browne, "First-best equilibrium in insurance markets with transaction costs and heterogeneity," Journal of Risk \& Insurance, vol. 74, no. 4, pp. 739-760, 2007.

[18] J. Neumann von and O. Morgenstern, The Theory of Games and Economic Behaviour, Princeton University Press, Princeton, NJ, USA, 1944.

[19] J. Nash, "Non-cooperative games," Annals of Mathematics, vol. 54, no. 2, pp. 286-295, 1951.

[20] R. C. Lewontin, "Evolution and the theory of games," Journal of Theoretical Biology, vol. 1, no. 3, pp. 382-403, 1961.

[21] J. M. Smith, "Game theory and the evolution of fighting," in On Evolution, pp. 8-28, Edinburgh University Press, Edinburgh, UK, 1972.

[22] J. M. Smith and G. R. Price, "The logic of animal conflict," Nature, vol. 246, no. 5427, pp. 15-18, 1973.

[23] J. M. Smith, "Evolutionary game theory," Physica D: Nonlinear Phenomena, vol. 22, no. 1-3, pp. 43-49, 1986.

[24] R. Axelrod and W. Hamilton, "The evolution of cooperation," Science, vol. 211, no. 4489, pp. 1390-1396, 1981.

[25] R. Sugden, The Economics of Rights, Co-operation and Welfare Basingstoke, Palgrave Macmillan, Basingstoke, UK, 2004.

[26] J. W. Weibull, "What have we learned from evolutionary game theory so far? (No. 487)," IUI Working Paper, 1997.

[27] D. Friedman, "On economic applications of evolutionary game theory," Journal of Evolutionary Economics, vol. 8, no. 1, pp. 15-43, 1998.

[28] J. W. Weibull, Evolutionary Game Theory, MIT Press, Cambridge, MA, USA, 1997.

[29] D. Friedman, "Evolutionary games in economics," Econometrica, vol. 59, no. 3, pp. 637-666, 1991.

[30] J. W. Weibull, Evolutionary Game Theory, MIT Press, Cambridge, MA, USA, 1997. 
[31] S. Qingwen, L. Liu, Y. Guangle, and C. Hongan, "A symptotic stability of evolutionary equilibrium under imperfect knowledge," Systems Engineering-Theory \& Practice, vol. 23, no. 7, pp. 11-16, 2003.

[32] Tort Policy Working Group, Report of the Tort Policy Working Group on the Causes. Extent, and Policy Implications of the Current Crisis in Insurance Availability and Affordability, US Department of Justice, Washington, DC, USA, 1986.

[33] J. P. Holland, "Professional liability of the architect and engineer," Journal of Professional Issues in Engineering, vol. 111, no. 2, pp. 57-65, 1985.

[34] A. H. Willett, The Economic Theory of Risk and Insurance, Reprint, Richard D. Irwin Inc, Homewood, IL, USA, 1901.

[35] C. Barker, "Social insurance and economic security," Yale Journal of Biology and Medicine, vol. 7, no. 2, p. 187, 1934.

[36] W. H. Mulligan, "Essentials of insurance law," Fordham Law Review, vol. 26, no. 4, p. 734, 1957.

[37] F. James, "Accident liability reconsidered: the impact of liability insurance," Yale Law Journal, vol. 57, no. 4, pp. 549-570, 1948.

[38] R. E. Keeton, "Liability insurance and responsibility for settlement," Harvard Law Review, vol. 67, no. 7, pp. 1136-1186, 1954.

[39] B. C. Darling, “Advice and warning regarding professional liability insurance: at the meeting of special committee on laboratories," Medical Society of the County of New York, vol. 21, p. 1924, 1925.

[40] J. F. Sadusk Jr., H. Hassard, and R. Waterson, "Analysis of your professional liability insurance policy," California Medicine, vol. 88, no. 1, p. 73, 1958.

[41] Risk Control in Professional Liability Insurance, Duke Law Journal, vol. 9, no. 1, pp. 106-126, 1960.

[42] C. F. Relyea, "Municipal corporations: waiver of immunity to suit by purchase of liability insurance," Michigan Law Review, vol. 52, no. 3, pp. 457-459, 1954.

[43] S. Harrington and R. Litan, "Causes of the liability insurance crisis,” Science, vol. 239, no. 4841, pp. 737-741, 1988.

[44] C. R. Heuer, "No liability insurance? limit your exposure to legal claims," Journal of Management in Engineering, vol. 3, no. 1, pp. 3-7, 1987.

[45] D. Oughton, "Expanding tort liability in English law and compulsory insurance for professional risks," Geneva Papers on Risk and Insurance - Issues and Practice, vol. 14, no. 4, pp. 331-346, 1989.

[46] R. W. Day, "Strict liability in civil engineering practice," Journal of Professional Issues in Engineering Education and Practice, vol. 119, no. 2, pp. 134-137, 1993.

[47] S. Shavell, Economic Analysis of Accident Law, Harvard University Press, Cambridge, MA, USA, 2009.

[48] R. A. Winter, "The liability insurance market," Journal of Economic Perspectives, vol. 5, no. 3, pp. 115-136, 1991.

[49] K. S. Abraham, "Making sense of the liability insurance crisis," Ohio State Law Journal, vol. 48, p. 399, 1987.

[50] K. S. Abraham, "The causes of the insurance crisis," Equity \& Excellence in Education, vol. XII, no. 4, pp. 46-48, 1974.

[51] L. A. Berger, J. D. Cummins, and S. Tennyson, "Reinsurance and the liability insurance crisis," Journal of Risk and Uncertainty, vol. 5, no. 3, pp. 253-272, 1992.

[52] ASCE Committee on Professional Practice, "Constituent committee on business practices and practice guidelines. Mitigating professional liability for civil engineers: white paper," Leadership and Management in Engineering, vol. 4, no. 4, pp. 141-147, 2004.
[53] M. F. Lunch, "Liability crisis-where do we go from here?," Journal of Performance of Constructed Facilities, vol. 1, no. 1, pp. 30-34, 1987.

[54] G. L. Priest, "The current insurance crisis and modern tort law," Yale Law Journal, vol. 96, no. 7, pp. 1521-1590, 1987.

[55] R. A. Rubin, "Liability insurance for design professionals: can't live with it, can't live without it?," Journal of Management in Engineering, vol. 10, no. 2, pp. 18-23, 1994.

[56] M. C. Loulakis and L. P. Mclaughlin, "Can a design professional be liable to third parties for negligence?," Civil Engineering Magazine Archive, vol. 75, no. 3, p. 96, 2005.

[57] J. S. Russell, "Insurance industry: overview," Journal of Management in Engineering, vol. 7, no. 1, pp. 98-118, 1991.

[58] D. J. Taylor, "Common legal doctrines and insurance issues affecting the forensic structural engineer," in Proceedings of the Forensic Engineering 2012: Gateway to a Safer Tomorrow, pp. 358-369, San Francisco, CA, USA, November 2013.

[59] J. Ittmann, C. J. Friedland, and A. M. Okeil, "Enforceability of limitation of liability clauses in engineering contracts," Journal of Legal Affairs and Dispute Resolution in Engineering and Construction, vol. 5, no. 3, pp. 128-135, 2013.

[60] C. P. Caine and H. R. Thomas, "Negligent tort liability of the design professional," Journal of Legal Affairs and Dispute Resolution in Engineering and Construction, vol. 5, no. 1, pp. 45-52, 2012.

[61] M. S. High and P. Rossler, "Engineering malpractice: avoiding liability through education," in Proceedings of the 2007 Annual Conference \& Exposition (ASEE Conferences), Honolulu, HI, USA, June 2007.

[62] A. E. Davis, "Professional liability insurers as regulators of law practice," Fordham Law Review, vol. 65, p. 209, 1996.

[63] R. E. Anderson, "Effective legal reform and the malpractice insurance crisis," Yale Journal of Health Policy, Law, and Ethics, vol. 5, no. 1, pp. 343-355, 2005.

[64] R. J. Bagby, A. Dudley, A. H. Porter, L. R. Muroff, R. Entel, and R. Maloy, "The Florida Radiological Society's efforts to correct the professional liability insurance crisis," Journal of the American College of Radiology, vol. 1, no. 5, pp. 364-365, 2004. 


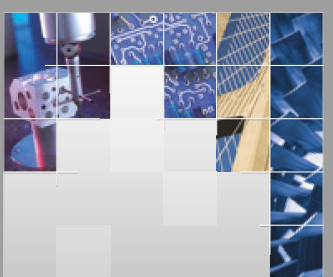

\section{Enfincering}
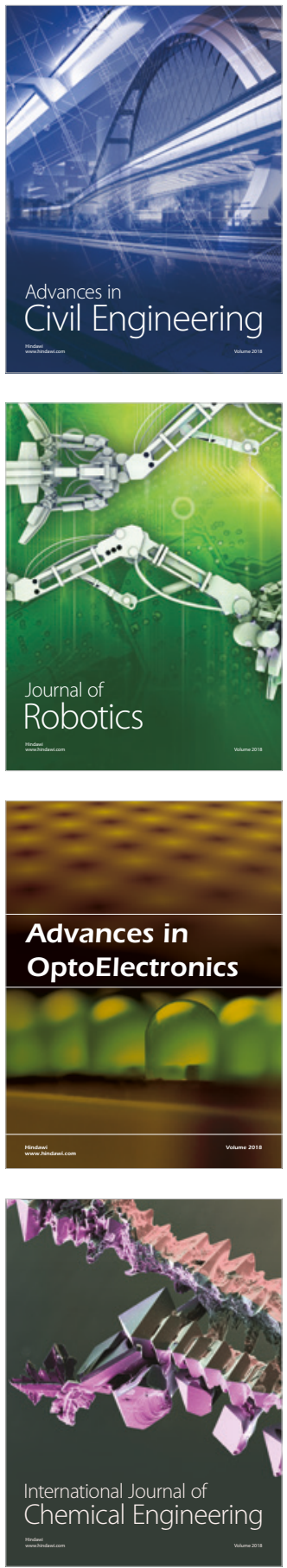

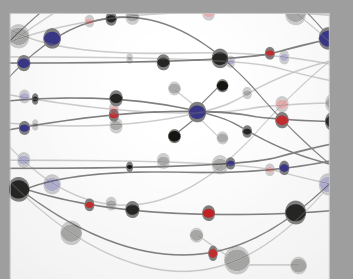

\section{Rotating \\ Machinery}

The Scientific World Journal

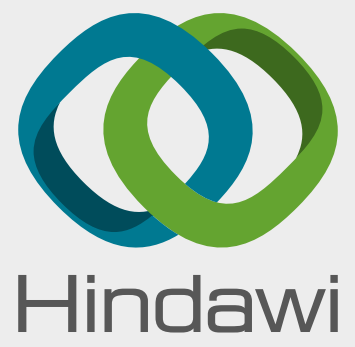

Submit your manuscripts at

www.hindawi.com
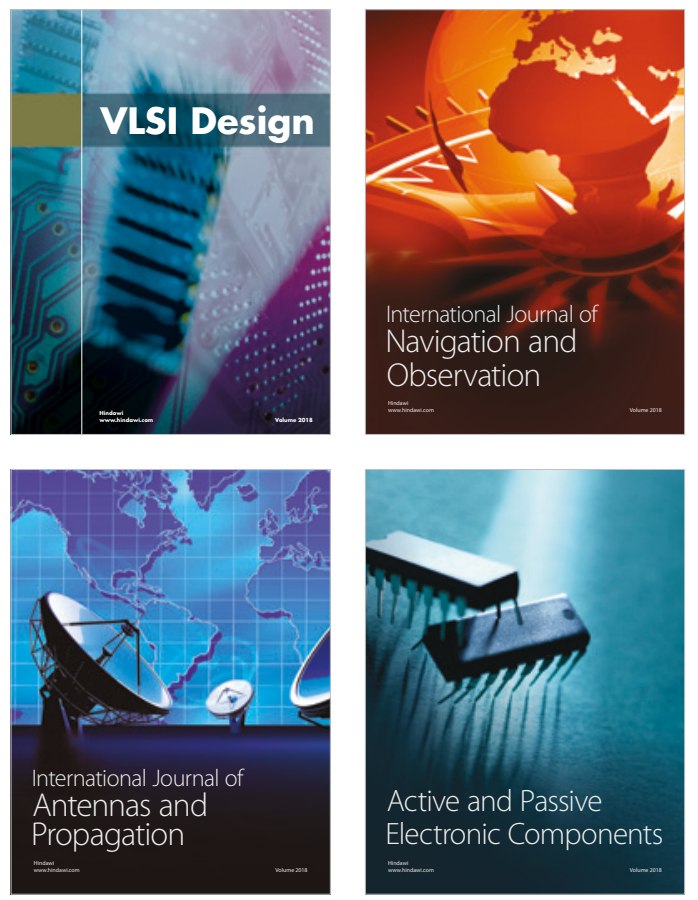
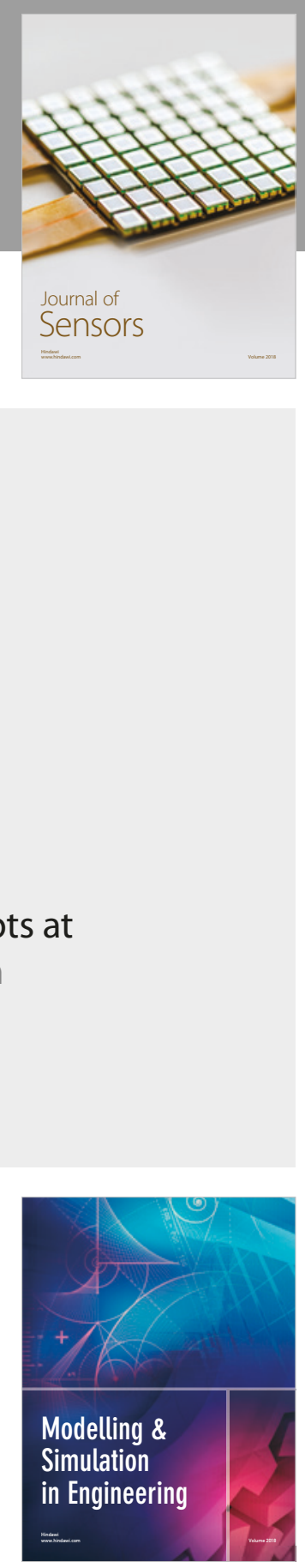

\section{Advances \\ Multimedia}
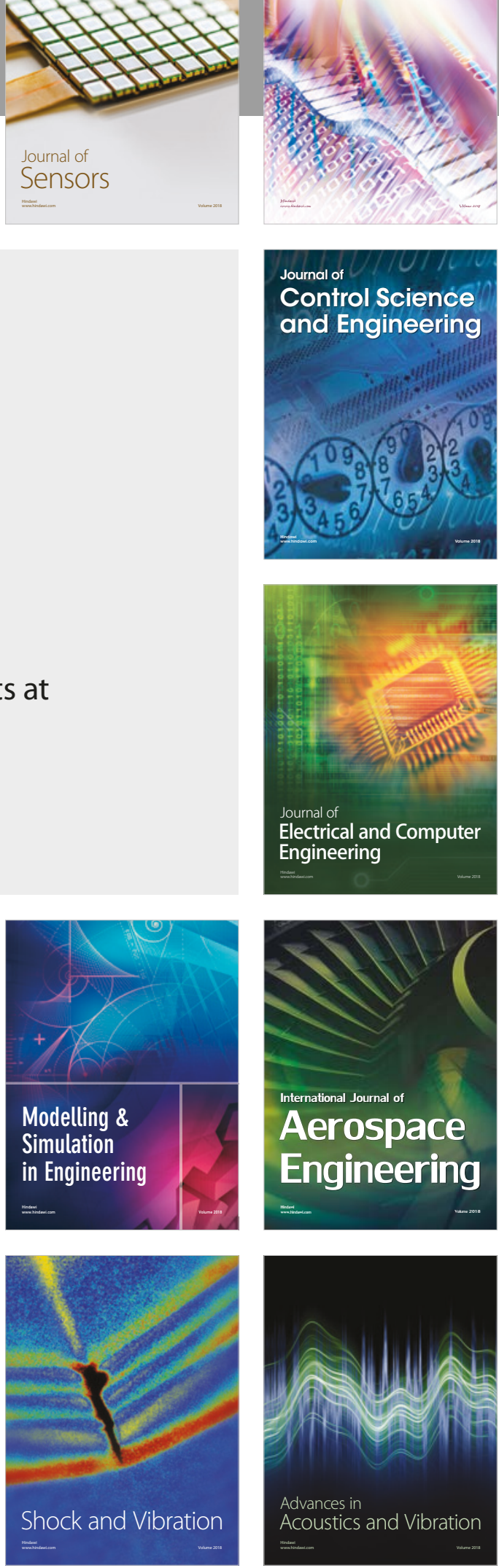